\title{
Opposite outcomes of social media use: A proposed model
}

\author{
Rita Rocha-Penedo ${ }^{1}$, Frederico Cruz-Jesus ${ }^{2 *}$, Tiago Oliveira ${ }^{3}$ \\ 1m2018635@novaims.unl.pt, 2fjesus@novaims.unl.pt/ORCID 0000-0002-4446-5980, \\ 3toliveira@novaims.unl.pt/ ORCID 0000-0001-6523-0809
}

1,2,3 NOVA Information Management School (NOVA IMS), Universidade Nova de Lisboa, Campus de Campolide, 1070-312 Lisboa, Portugal

This is the Author Peer Reviewed version of the following chapter/conference contribution published by Springer:

Rocha-Penedo, R., Cruz-Jesus, F., \& Oliveira, T. (2021). Opposite Outcomes of Social Media Use: A Proposed Model. In S. K. Sharma, Y. K. Dwivedi, B. Metri, \& N. P. Rana (Eds.), Re-imagining Diffusion and Adoption of Information Technology and Systems: A Continuing Conversation - IFIP WG 8.6 International Conference on Transfer and Diffusion of IT, TDIT 2020, Proceedings (pp. 524-537). (IFIP Advances in Information and Communication Technology; Vol. 618). Springer. https://doi.org/10.1007/978-3030-64861-9 46

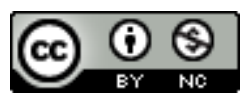

This work is licensed under a Creative Commons Attribution-NonCommercial 4.0 International License. 


\title{
Opposite outcomes of social media use: A proposed model
}

\author{
Rita Rocha-Penedo ${ }^{1}$, Frederico Cruz-Jesus ${ }^{2 *}$, Tiago Oliveira ${ }^{3}$

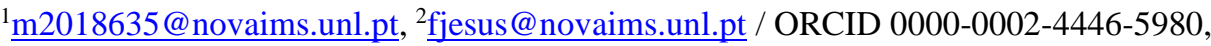 \\ ${ }^{3}$ toliveira@novaims.unl.pt / ORCID 0000-0001-6523-0809 \\ 1,2,3 NOVA Information Management School (NOVA IMS), Universidade Nova de \\ Lisboa, Campus de Campolide, 1070-312 Lisboa, Portugal
}

\begin{abstract}
Social media are probably one of the most influential and disruptive technology of the present times. It is ubiquitous and has the capability to influence virtually every aspect of one's life while, at the same time, also influence the way firms and public organizations operate and communicate with individuals. Although there is a plethora of studies in the IS literature focused on SM adoption and outcomes, studies hypothesizing positive and negative outcomes together are scarce. We propose a comprehensive research model to shed light on SM positive and negative outcomes, and how these affect one's happiness. We also explore how personality traits can influence these relationships.
\end{abstract}

Keywords: Social Media, Outcomes, Happiness, Personality Traits

\footnotetext{
* Corresponding author.
} 


\section{Introduction}

Social media (SM) are ubiquitous. They are increasingly important as mean of communication and information access [1]. SM already changed the way individuals, organizations, and governments, interact, produce, and consume information. These platforms enable people to chat through real-time instant message, create and share content, read news, build online relationships, gamming, post photos, videos and thoughts, under social, emotional and educational intentions [2]. SM use represent an opportunity for users to fulfil their social interaction needs and find solutions for their problems and daily tasks. However, they also entail several possible threats to its users. A decade ago, the presence of SM as we know nowadays, was unthinkable. According to the European Union, in 2010, less than one billion people were using SM platforms and in 2018 the number passed the three billion users. This growth of users is due to the increase in the time that people spend online [3].

In the information systems (IS) literature, research on SM have mainly focused on its adoption drivers and/or some specific outcomes. However, this fact entails a big caveat: SM are ubiquitous and multipurpose technologies, and can therefore affect, in a positive or negative way, virtually every dimension of one's life. When virtually every study focuses on one specific outcome, only a partial view of the picture is shown, thus hiding other opposite outcomes these technologies may yield in one's life. To fill this gap, the present research aims to develop a research model to shed light on how SM can yield different (positive and negative) outcomes and how these can ultimately affect one's happiness. We also assess the role that personality traits have on these relationships. In doing so, this paper is organized as follows: Section two presents the literature review for SM and SM outcomes; Section 3 introduces the model and the propositions; Section 4 its perspective implications; whereas Section 5 the conclusions and future work.

\section{Literature Review}

\subsection{Social Media}

Before the 1990's, mobile phones and Internet were only available to a non-significant part of world population [4]. The appearance of Information and Communication Technologies (ICT) made a revolution on contemporary society, emerging as new ways for individuals and businesses to perform daily tasks [5]. ICT diffusion around the world, had impact on economic growth on areas where access to communication and information were essential for a successful development [6]. From the way people communicate and spend free time, to the way people search and share information, the appearance of Internet came to change individuals' daily realities, "becoming one of the most dominant tools for social interaction". Internet enabled the creation of new technological environments like "blogs, social networking sites, virtual social worlds, collaborative projects, content communities and virtual game worlds", representing a new channel for authentic behaviour. Social sharing applications allowed Internet usage to skip from a read-only phase, Web 1.0, in the early 90s', to a read-write phase, Web 
2.0, in the beginning of 21 st century, enabling users to present and participate on content creation [7].

The concepts and technical basis of Web 2.0, qualified the creation of SM as online platforms, with origin on a "group of Internet-based applications" [8], where users can create and share content in a way to maintain online relationships with their family and friends and also to stablish new social connections [9]. The fact that each user can generate and share personal content in a public way, is the key factor that separate SM from other ways of traditional media [10]. This activities allow individuals to build social laces, with people with similar interests, based on opinions, knowledge and information sharing [11], constructed under social, emotional and educational intentions [2]. The connection between the offline persona and the online profile is kept by "the use of one's real name, recognizable pictures that make a user visually identifiable, and the presence of real-world acquaintances such as friends and family in the user's friends list" [12].

Myspace was the first social network site to reach a huge amount of popularity among Internet users but ultimately lost this position to Facebook. New SM sites intend now to reach users' time and attention, focusing on niches of individuals, instead of trying to replace the existing social networks [13]. Nowadays, users have a variety of choices according to their use objectives. An individual can use Facebook to share personal interests and keep in touch with family and friends [14]. Instagram provides fun and entertainment through creative content [15]. If users pretend to find a new job opportunity, share professional experiences or keep in touch with former colleagues, they can use LinkedIn [16].

SM represents a tool where users can satisfy their needs of entertainment, information, free time [17] or "to improve their performance to find solutions to problems for their daily or difficult tasks" [18]. Motivations to use SM, vary among social platforms and for different types of individuals, as people chose the one/ones to adopt basing on their personal needs and under influence of their social and psychological characteristics [15], [19]. The applicability of SM is present in several areas: political, education, health, etc. For instance, SM platforms allow brands to collaborate in a new consumer experience, creating fan pages to develop and advertise their products [20]. In the health field, [21] showed that, the more an individual uses SM, more likely he is to access online health information (nutrition, tobacco use or general health maintenance). In 2004, blogs became a part of US election campaigns. However, the Obama's 2008 US presidential elections were remarkable using SM like Facebook, YouTube, Myspace, and Flickr, as a source of news and marketing tool, representing the first 'SM election'. This example of success, was followed, not only in 2016 US presidential elections, by Hilary Clinton and Donald Trump, but as well as, Norway and U.K. parties [22]. The use of SM during disaster management, also revels to be very helpful, once that these platforms represent a way of fast information diffusion. During hurricane Sandy (2012) and Louisiana floods (2016), a big amount of information, regarding emergency shelters and medical services, was spread through Facebook and Twitter profiles and after Haiti earthquake (2010) SM channels, were used to gather donations [23], [24].

\subsection{Social media outcomes}

SM outcomes have been studied thoroughly during these past years. However, the research question is often postulated in terms of a specific outcome (positive or negative) 
can be achieved through SM use: some researchers have an optimistic approach, i.e., test beneficial effects that SM bring to people's lives, whereas others hold the idea that these platforms have a major negative impact for its users. People's skills and what they do online influence the benefits and arms they will obtain upon SM use. However, to feel completely satisfied with the outcomes achieved, Internet skills are more important [25]. It is noticeable by screening the literature that few, to say the least, empirically show that SM can yield both. For a review of studies focused on SM outcomes, please see Table 1.

Most studies involve the impact on well-being and psychological levels. Some researchers argue that Internet experiences have a key role in addiction behaviour development [26]. Compulsive SM use has been found to be related with higher levels of technostress, SM fatigue, which is a sentiment of mental exhaustion after experiencing an overload of information, and fear of missing out, described as the pervasive apprehension that an individual is absent from an rewarding experience that others might be having. These behaviors might generate anxiety, depression, lower-levels of happiness and individual performance, later bedtimes and shorter sleep duration, especially in adolescents and young adults [10], [27]-[29]. Although, fear of missing out is largely indicated as a negative driver, in some cases can be a good predictor to enhance social connection [30].

Potential opposite outcomes are also noticeable in terms of individuals' productivity (i.e., job performance, satisfaction, or academic achievement). Some researchers posit that the hedonic motivation, a driver of socialization and entertainment, associated with personal purposes, can affect work demand and job performance [31]. On the other hand, there is evidence that use SM at work, allow employees to connect with their family and friends, keeping a balance between work and personal life, reflecting in a larger concentration at work and revealing a positive association between job satisfaction and job performance [9]. This positive idea is supported by other studies, which find another import conclusions regarding the use of these platforms in professional domain, like, the influence of SM in increasing social capital or the opportunity to use SM as a tool to watch market competitors [16], [17].

Positive benefits regarding individual's social relations, well-being and lifestyle are also found in previous research. SM use contributes to several positive social outcomes like increased contact with family and friends, creation of online relations that may continue offline, sharing and getting new life experiences (travels, hotels, restaurants, brands, etc.) or information and knowledge trade off among social group communities [32]-[34].

Table 1. Literature review on social media outcomes.

\begin{tabular}{cclc}
\hline $\begin{array}{c}\text { Broad } \\
\text { outcome }\end{array}$ & $\begin{array}{c}\text { Specific } \\
\text { Outcomes }\end{array}$ & Findings & Ref. \\
\hline \multirow{3}{*}{ Psychological } & $\begin{array}{c}\text { Psychological } \\
\text { Dependence }\end{array}$ & $\begin{array}{l}\text { Internet experiences revealed to develop an addiction behaviour; The habit created } \\
\text { by the maximization of media use, drives to dependence. }\end{array}$ & {$[26]$} \\
\cline { 2 - 5 } & $\begin{array}{c}\text { Social Media } \\
\text { Fatigue }\end{array}$ & $\begin{array}{l}\text { SM users that think that is helpful to use SM platforms consequently experience } \\
\text { higher levels of SM fatigue. }\end{array}$ & $\begin{array}{l}\text { Compulsive use of SM and fear of missing out conduct to SM fatigue, that } \\
\text { consequently leads to anxiety and depression. }\end{array}$ \\
\cline { 2 - 5 } & Technostress & Higher levels of SM use, are associated with higher technostress. & {$[27]$} \\
\hline
\end{tabular}




\begin{tabular}{|c|c|c|c|}
\hline & $\begin{array}{l}\text { Positive and } \\
\text { Negative } \\
\text { Affect }\end{array}$ & $\begin{array}{l}\text { Authenticity in using SM platforms have a positive longitudinal effect on positive } \\
\text { affect and a negative longitudinal effect on negative affect. }\end{array}$ & {$[12]$} \\
\hline & $\begin{array}{l}\text { Psychological } \\
\text { Well-Being }\end{array}$ & $\begin{array}{l}\text { There is evidence to defend that SM use may have a positive effect on well-being, } \\
\text { if the intention is to participate in social connections. }\end{array}$ & {$[30]$} \\
\hline & Strain & $\begin{array}{l}\text { Psychological strain is lower in employees' that have a higher SM use for } \\
\text { information-sharing. }\end{array}$ & {$[31]$} \\
\hline & Loneliness & Instagram addiction is positively related with loneliness. & [35] \\
\hline & Shyness & There is a positive relation between Instagram addiction and shyness. & [35] \\
\hline \multirow{12}{*}{ Productivity } & \multirow{4}{*}{$\begin{array}{c}\text { Task/Job } \\
\text { Performance }\end{array}$} & The use of SM is negatively associated with task performance. & {$[10]$} \\
\hline & & SM usage is related with a better work performance. & {$[17]$} \\
\hline & & $\begin{array}{l}\text { There is a positive association between SM use at work and job performance; SM } \\
\text { usage can create favorable conditions for a better performance on job-related tasks. }\end{array}$ & [9] \\
\hline & & $\begin{array}{l}\text { The excessive use of SM, especially for social and entertainment purposes, have a } \\
\text { negative impact on work demand. }\end{array}$ & {$[31]$} \\
\hline & $\begin{array}{c}\text { Professional } \\
\text { Informational } \\
\text { Benefits } \\
\end{array}$ & $\begin{array}{l}\text { LinkedIn and Twitter users revealed higher informational benefits than non-users; } \\
\text { SM users that have a professional knowledge sharing intention, report the highest } \\
\text { informational benefits. }\end{array}$ & {$[16]$} \\
\hline & $\begin{array}{c}\text { Job } \\
\text { Satisfaction } \\
\end{array}$ & There is a positive relation between SM use at work and job satisfaction. & \multirow{2}{*}{ [9] } \\
\hline & $\begin{array}{l}\text { Cognitive } \\
\text { Absorption }\end{array}$ & The direct relationship between SM use and cognitive absorption is not significant. & \\
\hline & $\begin{array}{l}\text { Technology- } \\
\text { Work } \\
\text { Conflict } \\
\end{array}$ & $\begin{array}{l}\text { Excessive social and hedonic causes are positively related with technology-work } \\
\text { conflict. }\end{array}$ & {$[31]$} \\
\hline & Performance & A compulsive use of SM leads to lower levels of social performance. & [36] \\
\hline & Connection & SM use is positively associated with social connection. & {$[30]$} \\
\hline & Support & Active users of SM benefit from social support. & {$[32]$} \\
\hline & Capital & Social capital is one of the benefits that SM users gain from SM activities. & {$[32]$} \\
\hline \multirow{5}{*}{$\begin{array}{l}\text { Overall } \\
\text { Happiness }\end{array}$} & \multirow{2}{*}{ Happiness } & Higher levels of SM use drive to lower levels of happiness. & [37] \\
\hline & & Image-based SM are positively associated with happiness. & {$[10]$} \\
\hline & \multirow{3}{*}{$\begin{array}{l}\text { Satisfaction } \\
\text { with Life }\end{array}$} & Image-based SM cultivates satisfaction with life. & [37] \\
\hline & & $\begin{array}{l}\text { Authenticity in using SM platforms contributes to well-being and have a positive } \\
\text { relationship with satisfaction with life. }\end{array}$ & {$[12]$} \\
\hline & & $\begin{array}{l}\text { There is an impact of Instagram addiction on life satisfaction through the negative } \\
\text { relation between Instagram addiction and academic performance and the positive } \\
\text { impact on loneliness and shyness. }\end{array}$ & {$[35]$} \\
\hline
\end{tabular}

\section{Research Model}

There is a plethora of studies in the IS literature concluding that SM can impact one's life in many different (and opposite) ways (please see Table 1). However, there is no evidence about how SM can yield simultaneous outcomes at the same time. From a psychological perspective, we can see that SM can lead people to experience SM fatigue [29], but at the job level, it can also be associated with higher job satisfaction [9]. From a social standpoint, people can feel more connected [30] or as they get addicted, they can feel lonely [35]. But can this take place in one individual concurrently? And if so, what is the overall outcome in the ultimate one, i.e., happiness? These questions remain to be answered, and our paper aims to provide a theoretical lens for them for subsequent empirical testing. Thus, in our model (please see Figure 1), we consider three specifics outcomes from the psychological, productivity and social dimensions and one general outcome related with overall life happiness.

The psychological effects of SM are contradictory. However, we believe that the more an individual uses SM, the more difficult will be for him/her organize and follow a structured daily routine, in which he/she will not include the regular presence of these 
platforms. There is evidence that frequent use of SM platforms can result in addiction [26]. In terms of productivity, Some authors observed that there is a positive relation between social and hedonic motives to use SM and technology-work conflict [31]. Although, it seems that people can lose on psychological stability and work performance, in a social way, individuals can gain on capital and support [32]. Probably, the ultimate goal of a human being is to be happy. In fact, "people are repulsed by unhappiness" [10]. We believe that psychological, professional, and social stabilities are main drives to achieve that state.

To capture the potential negative effects of social media in one's psychological wellbeing, we resort to the concept of technostress, operated as a second-order reflectiveformative construct (see Figure 1). Technostress can be defined as " any negative impact on attitudes, thoughts, behaviors, or body physiology that is caused either directly or indirectly by technology" [10]. Virtually every feature of every SM can drive individuals to be constantly alert to what it is happening with their connections, interfering with their current tasks. From here, it is easy to feel divide between the need of keep attention to the real world and the intention to just check on what others are virtually doing. Dhir et al. [27] concluded that, users that reveal an excessive use of SM and also be afraid of missing something on these platforms, can feel fatigued and consequently may experience anxiety or depression, which will subsequentially affect one's happiness. An illustrative example is the fact that many SM users claim they see their SM pages during the night, and it is the first thing they do in the morning. Hence, we hypothesize:

H1: Social media use is positively associated with technostress.

H2: Technostress is negatively associated with happiness.

Another important impact SM may have on individuals is in their performance, either professional or academic. Thus, we resort to the concept of individual performance to capture this effect. Individual performance is the degree to which an individual is successful in achieving a goal related with a task he/she is engaged with [17]. It shows the consequent impact of the technology, in this case SM platforms, on individuals' tasks [10], [38] concluded that task performance was negatively influenced by the use of SM. $\mathrm{Cao}$ and $\mathrm{Yu}$ [31] demonstrate that people who overly use SM, especially for hedonic reasons, reveal a negative effect on their work demand. Thereby, we believe that SM use will have a negative impact on one's performance, which will subsequentially negatively impact one's happiness. Consequently, we hypothesize:

H3: Social media use is negatively associated with individual performance.

\section{H4: Individual performance is positively associated with happiness}

As for the social dimension, we set social performance as being the way SM users "invoke different patterns of socialization beliefs and behaviors". More specifically, is the way individuals use SM to communicate and interact in a way to achieve social capital [25]. These platforms allow its users not only to keep in touch with their close friends and family, anyway anytime, but also to create social laces with other people that they first know online. SM set a new level on loving and friendly relationships. SM use is positively associated with social connection [30]. Hsu and Lin [32] showed that by 
engaging on SM activities, users benefit from social capital and support. Thus, we believe that the use of SM leads people to perform better regarding social relations, which in its turn will be positively associated with overall happiness. Therefore, we argue that:

H5: Social media use is positively associated with social performance.

H6: Social relations use is positively associated with happiness

It is reasonable to assume that the previously hypothesized relations can vary from individual to individual, i.e., with one's personality. In fact, it is even possible that some of the hypothesis in our research model can be reverted in individuals with some specific and highly distinctive personality traits. To comprise this important aspect in our research model, we use the Five Factor Model (FFM), arguably the most relevant model to capture one's personality and idiosyncrasy [39]. It comprises five main personality traits - extraversion, agreeableness, conscientiousness, neuroticism, and openness. In the IS literature, there is a growing interest of how these traits affect one's relation with technology, although past studies usually consider this aspect in the pre-adoption stage of a technology, whereas we argue it will also play a role in post-adoption [1], [5], [40], [41].

Extraverts are relaxed in the way they socially connect with others, they have positive emotions, are moved by new stimulus, are audacious, friendly, and loquacious, whereas introverts are typically silent and cautious [39]. Those who score high in extraversion tend to pay more attention to their image, relate with more people, and like to new more people. Thus, they are more likely to use ICT, including SM [40]. We argue extraverts are more prone than introverts to use SM in a more intensive and extensive way. As one of SM main functionalities is connecting (known and new) people, the stronger extraversion trait is, the more likely can SM use yield new and/or reinforced social relations. Extraverts value social relations more than introverts do. Thus, it is reasonable to assume that for an extrovert, social relations are more relevant to happiness than for an introvert person, meaning that as extraversion increases so does the importance of social relations on one's happiness. Note that SM provide or demand new ways of communication such as emails, instant messaging, video sharing, video-broadcast, among others. In the IS literature, extraversion has been proved to be positively associated with ICT [40] and SM [42] use. For all the above, we hypothesize:

H7a: Extraversion will moderate the effect of SM use on social performance, such that the relationship will be stronger among people with higher extraversion.

H7b: Extraversion will moderate the effect of social performance on happiness, such that the relationship will be stronger among people with higher extraversion.

Agreeableness refers to the level of one's understanding, compassion, clemency, and kindness [39], which echoes one's orientation to others [42]. Agreeableness is therefore related with having positive feelings in the relationships with others [43]. Those who score high on agreeableness also reveal a lower level of technology-related anxiety [44]. Moreover, it also seems plausible that those who are less agreeable may be more likely to have difficulties in relating with others in traditional (offline) ways. One of the most 
known aspects of SM is that in it, people are less constrained to behave in ways that outside the SM environment would never do as they are morally unacceptable. News companies all over the world were forced to disable the comments sections because of the aggressiveness people showed in it. SM comments (e.g., in Facebook) are abundantly filled of offenses and arguments despite the original content of the post. For this reason, we argue that those who tend to face others with a positive perspective, i.e., with compassion, are more exposed to the influence that social performance has on their SWL/happiness. Consequently, those who show low levels of compassion and clemency will not see its SWL/happiness influenced by social performance, as they will see others, especially who do not fit their views, as despicable. Thus, we believe:

H8: Agreeableness will moderate the effect of social performance on happiness, such that the relationship will be stronger among people with higher agreeableness.

Highly conscientious people are generally systematic, efficient and organized [39]. They are self-disciplined and self-driven; goal- and task-oriented (Barrick, 2001). Conscientiousness is often pointed as the strongest of the five personality trait, as it is associated with one's ability to define and achieve long-term objectives by being able to adapt their behavior to a multiple plethora of environments [43]. Hence, conscientiousness is important in the context of achieving outcomes one desires. We argue that conscientiousness is particularly important in the (negative) effect SM has on individual performance. It is well known that SM (excessive) use can lead to procrastination of non-hedonic tasks, whether job- or school-related. However, we believe, that this negative effect of SM will become weaker as conscientiousness increases. Highly conscientiousness individuals are more likely to cope with SM distraction effects. In fact, we believe it is possible that for very high conscientiousness people, SM can even improve individual performance. Thus, we hypothesize:

H9: Conscientiousness will moderate the effect of SM use on individual performance, such that the relationship will be weaker among people with higher conscientiousness.

Individuals who score high on neuroticism are typically more delicate and anxious, with a tendency to be concerned easily [39]. People who score high on neuroticism more prone to give in to impulses, deal poorly with stressful events, and deal emotionally to situation where most people would deal rationally [39]. Therefore, neurotic people are prone to undergo negative emotions in situations that they perceive to be hostile [43]. Research has shown that those who score high on neuroticism are more prone to show higher levels of computer anxiety [44]. Those with higher levels of neuroticism "are likely to view technological advances in their work as threatening and stressful, and to have generally negative thought processes when considering it" [45]. These authors have shown that those who score high on neuroticism are less likely to perceived usefulness in a collaborative system, like SM. Neurotic individuals are more prone to find a technology useless and therefore tend to think that SM can represent a threat. Thus:

H10a: Neuroticism will moderate the effect of SM use on technostress, such that the relationship will be stronger among people with higher neuroticism. 
H10b: Neuroticism will moderate the effect of SM use on social relations, such that the relationship will be weaker among people with higher neuroticism.

It seems reasonable to assume that the more neurotic one individual is, the more important technostress' (negative) influence in overall happiness will be, as the first two dimensions will feed each other in a snow-ball effect. Moreover, the potentially good impact of social relations in one's happiness will also be attenuated as neuroticism grow because more social relations will be perceived as more potential threats. Thus:

H1Oc: Neuroticism will moderate the effect of technostress on happiness, such that the relationship will be stronger among people with higher neuroticism.

H10d: Neuroticism will moderate the effect of social relations on happiness, such that the relationship will be weaker among people with higher neuroticism.

Finally, openness is one of the big five personality traits and represents one's receptivity to new ideas and experiences [39]. It is associated with broad interests, novelty seeking, creativity, curiousness, flexibility, and non-conformist [46], opposing with those who prefer stability [47]. Thus, openness is positively associated with SM adoption. Openness yields lower levels of computer anxiety [48], which work as a catalyst for users to take the most of SM potential to meet new people and find new interests. Open individuals are non-conformists and experimentalist in nature. It seems then natural that for open individuals, the social dimension also has a higher importance in overall happiness, Accordingly:

H11a: Openness will moderate the effect of SM use on social relations, such that the relationship will be stronger among people with higher openness.

H11b: Openness will moderate the effect of social relations on happiness, such that the relationship will be stronger among people with higher openness.

Social media use behavior will be measured through a reflective construct adapted from [49], which is considered to be the most successful model for technology adoption. We will also use a formative construct considering the intensity of use of the SM with more than 1 billion active users in 2019 according with Statista. Happiness will be measured using the Oxford Happiness Survey [50]. The research model can be seen in Figure 1. 


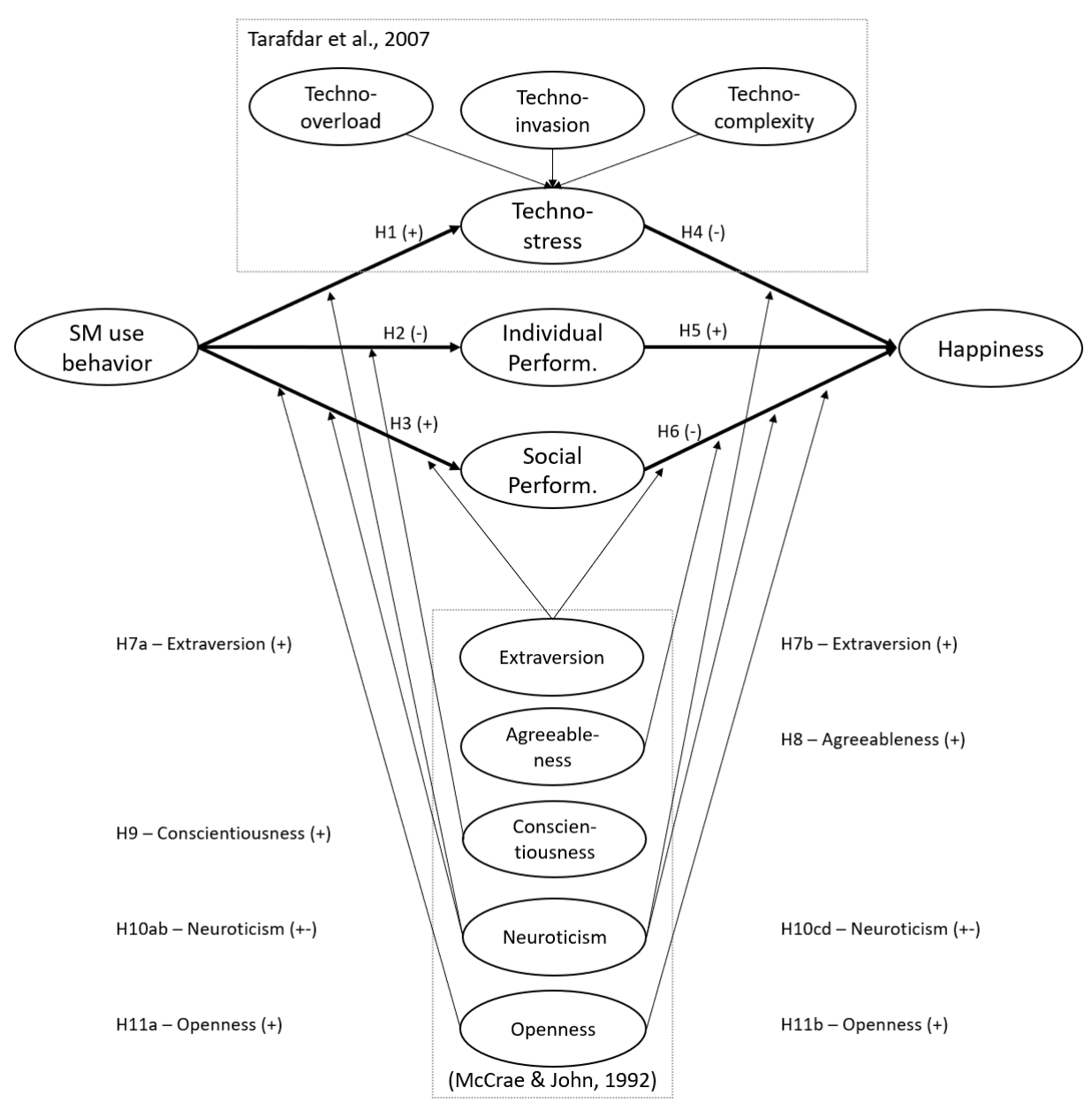

Fig. 1. Research model

\section{Perspective implications of the proposed model}

Understanding SM outcomes is an issue of special importance considering that in the last decade SM has emerged as a critical part of individuals', firms', and public organizations lives. This increasing widespread is related to the potential of SM to yield a plethora of (positive and negative) outcomes. To cope with these opportunities and threats SM comprise, we propose a research model to shed some light on this issue.

Our proposed model intends to help researchers and policymakers to better understand SM outcomes, to mitigate its negative and, at the same time, improve the positive outcomes. From the empirical validation of our model, and its hypotheses, we expect researchers, policymakers, and other stakeholders, to better understand how SM can be helpful and how it can be harmful. If we can do so, then a smoother and most effective SM influence in our lives may take place. For researchers, the perspective 
implications of our work lie in shed some light on the what is arguably the most influential technology of our times.

\section{Conclusions and future work}

We developed a research model that sheds light on how SM use yields different hypothesized outcomes and how these affect one's happiness. Moreover, we propose that personality traits can play a significant role in these relations. We believe that our model is tailor-made to SM in the sense that it will not be as effective if it is applied to other technological innovations. Overall, we developed 16 hypotheses. Six are directly between SM use and outcomes, whereas 10 are moderating effects. The model will be empirically tested using partial least squares structure equation modelling (PLS-SEM) using data collected in the European context.

\section{References}

[1] D. J. Hughes, M. Rowe, M. Batey, and A. Lee, "A tale of two sites: Twitter vs. Facebook and the personality predictors of social media usage," Comput. Human Behav., vol. 28, no. 2, pp. 561-569, 2012.

[2] A. E. E. Sobaih, M. A. Moustafa, P. Ghandforoush, and M. Khan, "To use or not to use? Social media in higher education in developing countries," Comput. Human Behav., vol. 58, pp. 296-305, 2016.

[3] E. Ortiz-Ospina, "The rise of social media," 2019. .

[4] D. W. Jorgenson and K. M. Vu, "The ICT revolution, world economic growth, and policy issues," Telecomm. Policy, vol. 40, pp. 383-397, 2016.

[5] G. Goncalves, T. Oliveira, and F. Cruz-Jesus, "Understanding individual-level digital divide: Evidence of an African country," Comput. Human Behav., vol. 87, no. March, pp. 276-291, 2018.

[6] P. Rsnen, "The aftermath of the ICT revolution? Media and communication technology preferences in Finland in 1999 and 2004," New Media Soc., vol. 10, no. 2, pp. 225-245, 2008.

[7] D. Rosen and C. Nelson, "Web 2.0: A new generation of learners and education," Comput. Sch., vol. 25, no. 3-4, pp. 211-225, 2008.

[8] E. W. T. Ngai, S. S. C. Tao, and K. K. L. Moon, "Social media research: Theories, constructs, and conceptual frameworks," Int. J. Inf. Manage., vol. 35, no. 1, pp. 33-44, 2015.

[9] P. Charoensukmongkol, "Effects of support and job demands on social media use and work outcomes," Comput. Human Behav., vol. 36, pp. 340-349, 2014.

[10] S. Brooks, "Does personal social media usage affect efficiency and well-being?," Comput. Human Behav., vol. 46, pp. 26-37, 2015.

[11] C. S. Lee and L. Ma, "News sharing in social media: The effect of gratifications and prior experience," Comput. Human Behav., vol. 28, no. 2, pp. 331-339, 2012.

[12] L. Reinecke and S. Trepte, "Authenticity and well-being on social network sites: A twowave longitudinal study on the effects of online authenticity and the positivity bias in SNS communication," Comput. Human Behav., vol. 30, pp. 95-102, 2014.

[13] K. Mcintyre, "The Evolution of Social media from 1969 to 2013," J. Soc. Media Soc., vol. 3, no. 2, pp. 5-24, 2014.

[14] T. M. Dumas, M. Maxwell-Smith, J. P. Davis, and P. A. Giulietti, "Lying or longing for likes? Narcissism, peer belonging, loneliness and normative versus deceptive like- 
seeking on Instagram in emerging adulthood," Comput. Human Behav., vol. 71, pp. 110, 2017.

[15] P. Sheldon and K. Bryant, "Instagram: Motives for its use and relationship to narcissism and contextual age," Comput. Human Behav., vol. 58, pp. 89-97, 2016.

[16] S. Utz, "Is LinkedIn making you more successful? The informational benefits derived from public social media," New Media Soc., vol. 18, no. 11, pp. 2685-2702, 2016.

[17] I. Leftheriotis and M. N. Giannakos, "Using social media for work: Losing your time or improving your work?," Comput. Human Behav., vol. 31, no. 1, pp. 134-142, 2014.

[18] E. C. Idemudia, M. S. Raisinghani, and O. Samuel-Ojo, "The contributing factors of continuance usage of social media: An empirical analysis," Inf. Syst. Front., vol. 20, no. 6, pp. 1267-1280, 2018.

[19] P. Sheldon, P. A. Rauschnabel, M. G. Antony, and S. Car, "A cross-cultural comparison of Croatian and American social network sites: Exploring cultural differences in motives for Instagram use," Comput. Human Behav., vol. 75, pp. 643-651, 2017.

[20] S. C. Chen and C. P. Lin, "Understanding the effect of social media marketing activities: The mediation of social identification, perceived value, and satisfaction," Technol. Forecast. Soc. Change, vol. 140, no. July 2018, pp. 22-32, 2019.

[21] R. S. Mano, "Social media and online health services: A health empowerment perspective to online health information," Comput. Human Behav., vol. 39, pp. 404-412, 2014.

[22] G. Enli, "Twitter as arena for the authentic outsider: exploring the social media campaigns of Trump and Clinton in the 2016 US presidential election," Eur. J. Commun., vol. 32, no. 1, pp. 50-61, 2017.

[23] K. C. Roy, S. Hasan, A. M. Sadri, and M. Cebrian, "Understanding the efficiency of social media based crisis communication during hurricane Sandy," Int. J. Inf. Manage, vol. 52, no. August 2018, 2020.

[24] J. Kim and M. Hastak, "Social network analysis: Characteristics of online social networks after a disaster," Int. J. Inf. Manage., vol. 38, no. 1, pp. 86-96, 2018.

[25] A. J. A. M. Van Deursen and E. J. Helsper, "Collateral benefits of Internet use: Explaining the diverse outcomes of engaging with the Internet," New Media Soc., vol. 20, no. 7, pp. 2333-2351, 2018.

[26] C. Wang, M. K. O. Lee, and Z. Hua, "A theory of social media dependence: Evidence from microblog users," Decis. Support Syst., vol. 69, pp. 40-49, 2015.

[27] A. Dhir, Y. Yossatorn, P. Kaur, and S. Chen, "Online social media fatigue and psychological wellbeing - A study of compulsive use , fear of missing out , fatigue , anxiety and depression," Int. J. Inf. Manage., vol. 40, no. December 2017, pp. 141-152, 2018.

[28] H. Scott and H. C. Woods, "Fear of missing out and sleep: Cognitive behavioural factors in adolescents' nighttime social media use," J. Adolesc., vol. 68, no. July, pp. 61-65, 2018.

[29] L. F. Bright, S. B. Kleiser, and S. L. Grau, "Too much Facebook? An exploratory examination of social media fatigue," Comput. Human Behav., vol. 44, pp. 148-155, 2015.

[30] J. A. Roberts and M. E. David, "The Social Media Party: Fear of Missing Out (FoMO), Social Media Intensity, Connection, and Well-Being," Int. J. Hum. Comput. Interact., vol. 36, no. 4, pp. 386-392, 2020.

[31] X. Cao and L. Yu, "Exploring the in fl uence of excessive social media use at work: A three- dimension usage perspective," Int. J. Inf. Manage., vol. 46, no. July 2018, pp. 8392, 2019.

[32] C. Hsu and J. C. Lin, "Antecedents and gains of user participation in social media in Taiwan,” Technol. Soc., vol. 61, no. February, 2020.

[33] A. J. A. M. van Deursen and E. J. Helsper, "The Third-Level Digital Divide: Who Benefits Most from Being Online?," Commun. Inf. Technol. Annu., pp. 29-52, 2015.

[34] M. Workman, "New media and the changing face of information technology use: The 
importance of task pursuit, social influence, and experience," Comput. Human Behav., vol. 31, no. 1, pp. 111-117, 2014.

[35] S. Ponnusamy, M. Iranmanesh, B. Foroughi, and S. S. Hyun, "Drivers and outcomes of Instagram Addiction: Psychological well-being as moderator," Comput. Human Behav., vol. 107, no. May 2019, 2020.

[36] V. Benson, C. Hand, and R. Hartshorne, "How compulsive use of social media affects performance: insights from the UK by purpose of use," Behav. Inf. Technol., vol. 38, no. 6, pp. 549-563, 2019.

[37] M. Pittman and B. Reich, "Social media and loneliness: Why an Instagram picture may be worth more than a thousand Twitter words," Comput. Human Behav., vol. 62, pp. 155167,2016

[38] C. Tam and T. Oliveira, "Does culture influence m-banking use and individual performance?," Inf. Manag., vol. 56, no. 3, pp. 356-363, 2019.

[39] R. R. McCrae and O. P. John, "An Introduction to the Five-Factor Model and Its Applications," J. Pers., vol. 60, pp. 175-215, 1992.

[40] P. Chipeva, F. Cruz-Jesus, T. Oliveira, and Z. Irani, "Digital divide at individual level: Evidence for Eastern and Western European countries," Gov. Inf. Q., vol. 35, no. 3, pp. 460-479, Sep. 2018.

[41] Y. Amichai-Hamburger et al., "Psychological factors behind the lack of participation in online discussions," Comput. Human Behav., vol. 55, pp. 268-277, 2016.

[42] D. Liu and W. K. Campbell, "The Big Five personality traits, Big Two metatraits and social media: A meta-analysis," J. Res. Pers., vol. 70, pp. 229-240, 2017.

[43] C. G. DeYoung, "Cybernetic Big Five Theory," J. Res. Pers., vol. 56, pp. 33-58, 2015.

[44] A. Korukonda, "Personality, individual characteristics, and predisposition to technophobia: Some answers, questions, and points to ponder about," Inf. Sci. (Ny)., vol. 170, pp. 309-328, Feb. 2005.

[45] U. S. Devaraj, R. F. Easley, and J. Michael Crant, "How does personality matter? Relating the five-factor model to technology acceptance and use," Inf. Syst. Res., vol. 19, no. 1, pp. 93-105, 2008

[46] Y. Li, C.-H. Tan, H. Teo, and B. yeow Tan, "Innovative usage of information technology in Singapore Organizations: Do CIO characteristics make a difference?," Eng. Manag. IEEE Trans., vol. 53, pp. 177-190, Jun. 2006.

[47] H. S. Yoon and L. M. Barker Steege, "Development of a quantitative model of the impact of customers' personality and perceptions on Internet banking use," Comput. Human Behav., vol. 29, no. 3, pp. 1133-1141, 2013.

[48] A. R. Korukonda, "Differences that do matter: A dialectic analysis of individual characteristics and personality dimensions contributing to computer anxiety," Comput. Human Behav., vol. 23, no. 4, pp. 1921-1942, 2007.

[49] V. Venkatesh, J. Y. L. Thong, and X. Xu, "Consumer acceptance and use of information technology: Extending the unified theory of acceptance and use of technology," MIS Q. Manag. Inf. Syst., vol. 36, no. 1, pp. 157-178, 2012.

[50] P. Hills and M. Argyle, "The Oxford Happiness Questionnaire : a compact scale for the measurement of psychological well-being," vol. 33, pp. 1073-1082, 2002. 